\title{
A Graduação em Psicologia Prepara para o Trabalho no Hospital?
}

Does The Undergraduation Course In Psychology Prepare To The Work In A Hospital?

¿La Graduación En Psicología Prepara Para El Trabajo En El Hospital?
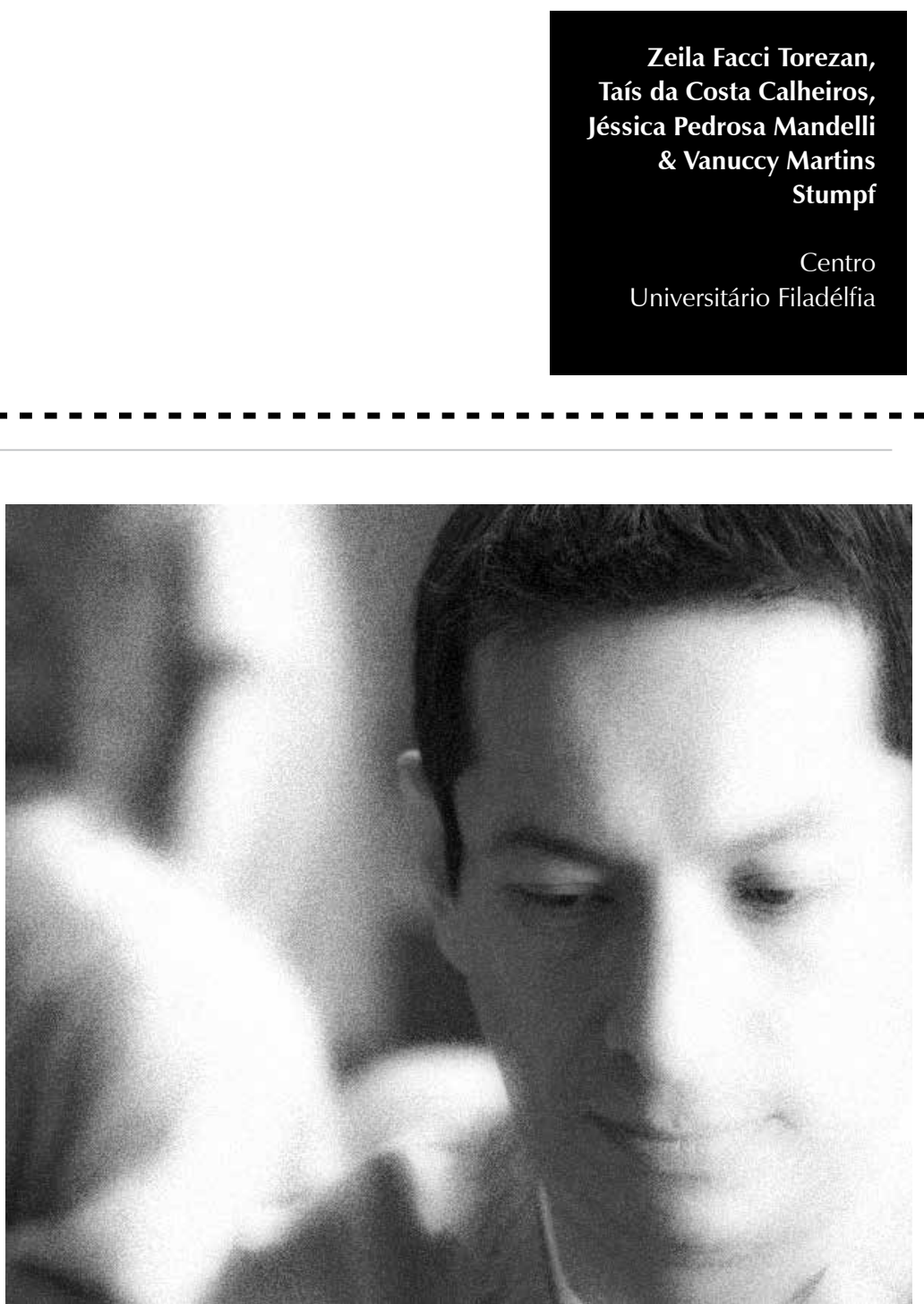
Resumo: Considerando a Psicologia hospitalar uma especialidade em expansão no campo da Psicologia da saúde, o presente trabalho resulta de uma pesquisa exploratória sobre a preparação na graduação dos psicólogos hospitalares, que verificou a relação da formação acadêmica com a prática em hospitais gerais na região de Londrina - PR. Participaram desta pesquisa 10 psicólogos hospitalares com vínculo empregatício de no mínimo seis meses e três coordenadores de cursos de graduação em Psicologia de Londrina. Para a coleta dos dados, foram utilizados dois questionários de entrevista semiestruturada que continham questões abertas e fechadas. O primeiro questionário levantou dados sobre a formação acadêmica e as funções desenvolvidas pelos psicólogos nos hospitais, e o segundo buscou informações referentes às oportunidades de formação voltadas para a área de saúde e ofertadas pelos cursos de Psicologia pesquisados. Também foi realizada consulta aos projetos pedagógicos dos referidos cursos. No universo pesquisado, constatou-se que, em geral, a formação na graduação em Psicologia não contempla as particularidades necessárias para o trabalho em hospital geral.

Palavras-chave: Psicologia da saúde. Psicologia hospitalar. Ensino superior. Formação do Psicólogo. Formação profissional.

\begin{abstract}
Considering hospital psychology as an expanding specialty in the broader field of health psychology, this paper results from an exploratory research about the undergraduation courses for the psychologists who work in hospitals, observing the relationship between academic formation and practice in general hospitals in Londrina - PR. Ten hospital psychologists with at least six months emplyment and three coordinators of undergraduation courses in psychology from Londrina participated in this study. The instruments used for data collection were two questionnaires of semi-structured interviews, containing open and closed questions. The first questionnaire collected data about the academic formation and the functions developed by psychologists in hospitals. The second questionnaire sought information regarding the formation opportunities related to the area of health, offered by the psychology courses that were researched. It was also performed a consultation of the educational projects of such courses. In the group studied, it was found that, in general, the undergraduation courses in Psychology do not address the specific skills for the work in a general hospital. Keywords: Health psychology. Hospital psychology. Undergraduation. Psychologist education. Professional education.
\end{abstract}

Resumen: Considerando la Psicología hospitalaria una especialidad en expansión en el campo de la Psicología de la salud, el presente trabajo resulta de una investigación exploradora sobre la preparación en la graduación de los psicólogos hospitalarios, que verificó la relación de la formación académica con la práctica en hospitales generales en la región de Londrina - PR. Participaron de esta investigación 10 psicólogos hospitalarios con vinculación laboral de por lo menos seis meses y tres coordinadores de cursos de graduación en Psicología de Londrina. Para la recolección de los datos, se utilizaron dos cuestionarios de entrevista semiestructurada que contenían preguntas abiertas y cerradas. El primer cuestionario relevó datos sobre la formación académica y las funciones desarrolladas por los psicólogos en los hospitales, y el segundo buscó informaciones referentes a las oportunidades de formación volcadas al área de la salud y ofrecidas por los cursos de Psicología investigados. También se realizó consulta a los proyectos pedagógicos de los referidos cursos. En el universo investigado, se constató que, en general, la formación en la graduación en Psicología no abarca las particularidades necesarias para el trabajo en hospitales generales.

Palabras clave: Psicología de la salud. Psicología hospitalaria. Enseñanza superiora. Formación del psicólogo. Educación profesonal.

O contato com espaços hospitalares é uma ocorrência possível na vida de qualquer ser humano, e a influência que exerce sobre o psiquismo faz-se notável. O trabalho de profissionais de Psicologia nesses espaços, aliado a outras especialidades, em uma intervenção interdisciplinar, compõe o contexto de atendimento aos pacientes e a seus familiares no âmbito hospitalar, tanto nas unidades ambulatoriais quanto nas de internação. Vale ressaltar que, no amplo contexto da Psicologia da saúde, a Psicologia hospitalar se caracteriza no Brasil como uma especialidade em notável crescimento e que demanda o exercício de habilidades específicas e variadas dos profissionais, gerando expectativas de que a formação acadêmica contemple os aspectos fundamentais para a atuação do psicólogo nos hospitais.

Historicamente determinados por uma visão vinculada a práticas de acolhimento espiritual e de cunho caritativo, as intervenções, os 
acompanhamentos e as escutas dos doentes passam a ter, com a Psicologia como ciência e profissão, uma fundamentação teóricocientífica. De acordo com Costa Júnior (2010), em 1911, a Associação Americana de Psicologia (APA) se reuniu para discutir a inclusão de aspectos do campo da Psicologia no curso de Medicina. Segundo Costa Júnior, houve, em 1916, uma proposta oficial da APA para o ensino de processos psicológicos a estudantes de Medicina e, posteriormente, tais disciplinas passaram a fazer parte desse currículo.

Por outro lado e no contexto brasileiro, por volta de 1968, as primeiras disciplinas relacionadas à saúde foram ministradas a estudantes de graduação de Psicologia na Universidade de São Paulo. Em 1995, a área da saúde passou a ser a segunda maior área em inserção de psicólogos da APA, e, em 1988, o Conselho Nacional de Saúde incluiu a Psicologia como área de conhecimento pertencente à saúde. A regulamentação da prática profissional do psicólogo se deu na década de 60 , momento em que o campo de atuação nos hospitais começa a definir-se. Conforme afirma Speroni (2000), no fim da década de 50 e durante a década de 60 , a Psicologia foi crescendo e inserindo-se no contexto do hospital geral. Desde então, a Psicologia hospitalar vem evoluindo no sentido de um refinamento teórico, da construção de um novo saber e da definição de uma identidade profissional.

O trabalho diferenciado e peculiar que o profissional de Psicologia pode desempenhar nos hospitais foi sendo delineado à medida que os médicos e os demais profissionais não sabiam como agir frente a situações que fugiam do âmbito puramente clínico e medicamentoso. Nesse sentido, a intervenção da psicóloga Mathilde Neder foi pioneira, pois, de acordo com o Conselho Federal de Psicologia (CFP) (2006, p. 20), essa profissional promoveu uma "silenciosa revolução no atendimento médico-hospitalar" ao escutar os pacientes em tratamento, aliando sensibilidade e conhecimentos técnicos, fundamentada no reconhecimento da dignidade humana. Com base no CFP, questionando o modelo biomédico, surge um modelo alternativo, biopsicossocial, que leva em consideração múltiplos aspectos da realidade existencial, com o entendimento de uma multideterminação mais complexa acerca dos possíveis fatores predisponentes e precipitantes do adoecimento.

Segundo a APA (1978 como citado em Costa Júnior, 1997), a Psicologia da saúde é um campo de contribuição, tanto científica quanto profissional, específico da Psicologia, tendo em vista fatores como promoção e manutenção da saúde e prevenção e tratamento de doenças, visando não apenas à recuperação, mas à prevenção e à manutenção da saúde. O psicólogo no contexto da saúde, conforme afirma Matarazzo (1980), irá desenvolver um conjunto de práticas educacionais, profissionais e científicas que objetivam promover e manter a saúde da população, além de prevenir e tratar as doenças, bem como deve ser capaz de efetuar uma análise do desenvolvimento do sistema de saúde e das políticas públicas que o regem.

Percebe-se que as funções desempenhadas pelo profissional de Psicologia são muito mais abrangentes do que aquelas referidas ao atendimento individual e de caráter psicoterápico, como é visto, frequentemente, nos modelos tradicionais clínicos e pertencentes a uma formação individualista e caracteristicamente vinculada ao modelo médico. Segundo Costa Júnior (1997), os modelos clínicos de atendimento dentro de um enfoque tradicional dão destaque ao estudo das patologias e não permitem a compreensão do fenômeno saúde-doença como um todo, restringindo-se, portanto, a indicações de morbidade e de mortalidade. Conforme afirma Gioia-Martins e Rocha 
(2001, p. 37), "todo cidadão tem de receber atenção e cuidados que Ihe garantam atendimento global", e esse novo paradigma biopsicossocial concebe o processo saúdedoença como fenômeno coletivo, histórico e multideterminado, o que traz a necessidade de se imprimir um caráter interdisciplinar e não dicotômico às áreas de conhecimento da saúde. De acordo com os autores, o novo paradigma não pode ser apenas científico, mas deve envolver e contemplar a própria realidade contemporânea em que se vive e se constrói a ciência, sem uma separação entre as ciências sociais e as naturais no entendimento dos processos psicológicos e do contexto de trabalho.

Sobre o aspecto de dicotomização das práticas psicológicas, Branco (1998) afirma que o fechamento, por parte dos profissionais, da área em seus pressupostos e práticas leva à fragmentação e ao fundamentalismo na atuação, que produzem um enrijecimento técnico, fator entendido como barreira para a construção da prática anteriormente citada. Moura (1999) comenta que os cursos de graduação em Psicologia, ao formularem seus currículos, se comprometem com uma vinculação articulada com os sistemas políticos vigentes, de forma a evitar e a descaracterizar qualquer tentativa de apropriação do aspecto social por parte dos psicólogos, apresentando uma formação reducionista e tecnicista, que se refletem no distanciamento teórico-conceitual e prático da profissão perante as demandas sociais de atenção à saúde.

A respeito da defasagem entre demandas e serviços prestados, segundo Costa Júnior, essa se deve ao despreparo do psicólogo para atuar na área de saúde, que, desde sua graduação, não desenvolve as competências necessárias para o desempenho do papel solicitado pelo sistema de saúde e das suas necessidades de atendimento. Outra dificuldade abordada é a falta de conhecimento geral desses profissionais com relação à metodologia científica e sua aplicação nas investigações sistemáticas e próprias dos contextos médicos, em esquemas multi e interdisciplinares (Costa Júnior, 1997). Esse aspecto científico e metodológico tido como deficitário nos egressos do curso de Psicologia não se aproxima de uma postura de rigidez conceitual ou de um distanciamento do paradigma holístico proposto anteriormente; pelo contrário, apresenta a necessidade de questionamento e de reconstrução dos conhecimentos em busca de um entendimento mais fidedigno a respeito dos fenômenos humanos e sociais, sem um posicionamento fundamentalista ou dogmático. A necessidade de formação dos graduandos a partir de atividades de pesquisa é uma temática já comentada por Weber (1985), pois, mais importante do que acrescentar à graduação novas disciplinas ou objetivos, as agências formadoras deveriam pensar sobre formas de estruturar o curso de Psicologia que possibilitassem a participação dos alunos no processo de construção do conhecimento.

Nessa perspectiva, Spink (2009) aponta que, diante de uma formação centrada na atuação clínica, no indivíduo e no consultório, é comum a transferência do referencial teórico para o contexto institucional de forma acrítica, na qual o psicólogo é tido como instrumento para a manutenção da proposta vigente. A autora ressalta que o trabalho em instituições de saúde requer expansões de referenciais em dois aspectos, sendo o primeiro vinculado à compreensão das determinações sociais mais amplas que influenciam na relação profissional entre psicólogo e cliente e o segundo, vinculado à aceitação da diversidade:

1) uma expansão do referencial contextual, ou seja, a busca de dados que permitam melhor localizar o psicólogo e seu cliente na dinâmica social e/ou institucional; 2) uma expansão do referencial teórico no sentido de conseguir trabalhar com a alteridade, 


\section{Conforme afirma \\ Minayo (2008), a coerência metódica e sistemática da investigação nas pesquisas em saúde é instrumental necessário para a aplicação da teoria.}

ou seja, com a perspectiva do "outro" definido culturalmente como diferente do "eu" (Spink, 2009, p. 134)

A partir das defasagens indicadas, pode-se formular a hipótese que o egresso do curso de graduação em Psicologia conclui seus estudos com uma visão limitada sobre a real atribuição de seu papel no grupo interdisciplinar, bem como sobre os entraves sociais e institucionais que perpassarão seu trabalho nas instituições hospitalares. Entretanto, nos últimos cinco anos, vem ocorrendo a ampliação da oferta de disciplinas obrigatórias e de estágios voltados para essa especialidade. Essas mudanças surgiram em virtude da publicação das Diretrizes Curriculares Nacionais para os cursos de graduação em Psicologia, denominada Resolução n.8 (2004), que estabelece os fundamentos e os princípios para a formação do psicólogo no Brasil.

Considerando os aspectos acima abordados, este estudo objetivou verificar de forma amostral se os psicólogos que atuam em hospitais da cidade de Londrina - PR consideravam que os saberes adquiridos na graduação em Psicologia os auxiliaram em sua atuação prática. Também foi objetivo deste estudo verificar se as grades curriculares dos cursos de graduação em Psicologia da mesma cidade contemplam disciplinas específicas e atividades aplicadas para o embasamento do trabalho do psicólogo em hospitais, conforme propõem as Diretrizes Curriculares para o curso de Psicologia.

\section{Método}

Conforme afirma Minayo (2008), a coerência metódica e sistemática da investigação nas pesquisas em saúde é instrumental necessário para a aplicação da teoria. Para tanto, realizou-se uma investigação exploratória a partir dos critérios da Resolução n. 8, tecendo-se uma análise comparativa das ementas dos cursos de Psicologia existentes no local da pesquisa com as informações coletadas junto a psicólogos que atuam no contexto hospitalar na mesma região. Também foi feito o levantamento das disciplinas e práticas de estágio presentes nas grades curriculares dos cursos de Psicologia de Londrina que contemplam a área da saúde e, especificamente, o campo hospitalar. Considerou-se a busca da correlação entre esses dados como possível agregadora de benefícios para os estudantes e profissionais da área e para as instituições responsáveis pela oferta e pelas reformulações dos cursos de graduação em Psicologia.

\section{Participantes}

A investigação proposta foi realizada com 13 participantes. Desse total, 10 participantes eram psicólogos com vínculo empregatício em hospitais gerais da cidade de Londrina há no mínimo seis meses. Esse critério objetivou estabelecer um tempo mínimo de experiência para que os participantes pudessem relatar aspectos de sua prática e uniformizar as condições de trabalho como de vínculo profissional formal, e não de condições de voluntariado ou de estágio. Observa-se que esses 10 participantes pertenciam a 5 instituições hospitalares da cidade em questão. Os demais participantes, 3, ocupavam a função de coordenadores de cursos de graduação em Psicologia de três faculdades da cidade de Londrina. Os 10 participantes que atuam em hospitais representam em torno de $70 \%$ do total de profissionais que atuam na área na cidade pesquisada, e a seleção dependeu da disponibilidade de ceder entrevistas e de acesso institucional. Quanto às instituições de ensino pesquisadas, na época da coleta de dados havia, além das três pesquisadas, mais uma de pequeno porte e que contemplava o curso de Psicologia em início de turmas, e que, por esses dois motivos, não foi incluída na pesquisa. 


\section{Instrumentos}

Foram elaborados dois tipos de questionários de entrevistas semiestruturadas, composto de questões abertas e fechadas, que foram respondidos pelos 10 participantes que trabalhavam em hospitais gerais (Anexo A) e pelos 3 coordenadores dos cursos de graduação em Psicologia (Anexo B). Conforme exposto no Anexo A, as questões dirigidas aos psicólogos foram elaboradas com o intuito de descrever o trabalho desenvolvido por eles nos hospitais e de levantar a importância ou não dos conhecimentos acadêmicos que receberam durante a graduação em Psicologia para o desempenho nesse contexto. O Anexo B permite ao leitor verificar que as questões que orientaram as entrevistas com os coordenadores tinham como objetivo principal identificar as disciplinas e as demais atividades curriculares que estivessem focadas na formação do psicólogo para atuar na área da saúde e, particularmente, nas instituições hospitalares. Embora os projetos pedagógicos e as grades curriculares dos cursos de graduação em Psicologia que participaram da pesquisa não se configurem como instrumentos de pesquisa, eles foram utilizados para a coleta de dados de forma a complementar às informações fornecidas pelos coordenadores dos referidos cursos.

\section{Procedimento}

Foram realizados contatos com os possíveis participantes de pesquisa por telefone e e-mail, esclarecendo os objetivos e os procedimentos da presente pesquisa e verificando a disponibilidade de os mesmos serem entrevistados. No caso dos coordenadores, além do agendamento da entrevista, foi solicitada a disponibilização dos projetos pedagógicos dos referidos cursos. Todos os 13 participantes desta pesquisa leram, receberam os esclarecimentos necessários, aprovaram e assinaram o
Termo de Consentimento Livre e Esclarecido, referendado pelo Comitê de Ética em Pesquisa com Seres Humanos (CEP), do Centro Universitário Filadélfia (UniFil), e foram informados sobre a devolutiva dos dados, realizada ao final da pesquisa via e-mail. Todas as entrevistas foram feitas por uma dupla de pesquisadores, sendo que, enquanto um verbalizava as questões ao entrevistado, o outro registrava os dados através de anotações, sem gravação em áudio, que ocorreram nos locais de trabalho dos participantes da pesquisa, sem a presença de outros observadores. Realizou-se a análise dos projetos pedagógicos e das grades curriculares dos cursos de graduação em Psicologia das três instituições de ensino superior da cidade de Londrina que participaram da pesquisa.

Foram elaboradas tabelas comparativas entre os participantes, de forma agregada entre os psicólogos hospitalares, e, na sequência, entre os coordenadores dos cursos. Para as questões fechadas, fez-se o cálculo de porcentagem dos dados, e, para as questões abertas, foram formuladas categorias de análise de conteúdo, geradas a partir dos objetivos propostos na pesquisa e de temáticas comuns abordadas pelos participantes. Para as entrevistas com os coordenadores, estas consistiram em: disciplinas obrigatórias, disciplinas optativas, estágios, projetos vinculados à saúde, horas totais de atividades nesse enfoque, alterações após a Resolução n. 8 e adequação dos conhecimentos ofertados na graduação para o exercício profissional em saúde. Nas entrevistas com os psicólogos, estas se referiram a: idade, sexo, tempo de formado, atividades na graduação relacionadas à saúde, atividades extracurriculares, função do psicólogo hospitalar, atividades exercidas nas intervenções, histórico institucional do serviço de Psicologia no seu contexto do trabalho, dificuldades encontradas e 
formação continuada. A análise das ementas curriculares buscou verificar: a carga horária, a distribuição ao longo do curso e os tipos de atividade na área de saúde.

Fez-se uma análise comparativa entre os resultados estatísticos, aqueles oriundos das categorias de análise, a análise das ementas dos cursos de graduação em Psicologia e os dados obtidos através da entrevista com os coordenadores de curso. Em uma primeira etapa, a análise circunscreveu-se aos conhecimentos exigidos pela Resolução n. 8 relacionados à área de saúde e àqueles presentes nas atividades curriculares dos cursos pesquisados, a fim de verificar a atualidade de tais projetos e a adequação destes às regulamentações nacionais. Dessa verificação, partiu-se para os dados estatísticos e demais resultados das entrevistas, tecendo relações possíveis entre eles. As discussões foram embasadas nos referenciais bibliográficos que sustentam a fundamentação teórica desta pesquisa, permitindo algumas considerações sobre a formação na graduação em Psicologia e a atuação profissional dos psicólogos em hospitais gerais de forma circunscrita à amostra pesquisada.

\section{Resultados}

Os psicólogos hospitalares entrevistados apresentaram idade média de 40 anos, sendo que cinco tinham 41 anos ou mais, dois apresentavam entre 36 e 40 anos, dois tinham entre 31 e 35 anos e apenas um afirmou ter idade entre 25 e 30 anos. Seis participantes estão formados há mais de 10 anos, dois deles há menos de 5 anos e 2 outros em um período entre 5 e 10 anos. Verificou-se que, dos 10 psicólogos hospitalares entrevistados, 7 não tiveram conhecimentos diretamente relacionados à prática profissional em hospitais ou outras instituições de saúde durante a graduação em Psicologia. Das atividades elencadas como significativas na graduação e que possam ter auxiliado na prática profissional no hospital, esses participantes indicaram que a formação em clínica foi relevante para essa atuação de escuta e de observação do outro ser humano em processo de adoecimento. Dois dos participantes afirmaram ter feito a ênfase no final do curso voltada para conhecimentos da área de saúde, em concordância com o indicado pela Resolução n. 8. Esses dois e outro psicólogo afirmaram ter cursado disciplinas obrigatórias e estágios no curso relacionados à área da saúde, e consideramse egressos devidamente preparados para o trabalho em hospitais.

Oito profissionais afirmaram que os congressos, eventos, cursos, estágios não obrigatórios, as leituras por interesses pessoais, a prática já no exercício da profissão, as orientações tidas com colegas, os grupos de estudos, a terapia individual, os atendimentos de supervisão com profissionais mais experientes, pósgraduações, o exercício profissional em outras instituições antes de ingressarem no hospital, bem como a experiência de anos na área clínica foram fundamentos sólidos para o exercício profissional coerente e consistente.

A respeito da função do psicólogo, cinco profissionais caracterizam-na como de escuta à população atendida no contexto hospitalar, dois entendem-na como de orientação e um profissional dá enfoque à preparação para intervenções, sendo que três deles não comentaram o assunto. Sobre as atividades que executam, especificamente, seis participantes afirmaram que trabalham com psicoterapia breve e seis com escuta analítica. Três intervêm com entrevistas iniciais, e oito psicólogos citaram as seguintes atividades, isoladamente: acolhimento, humanização, palestras, preparação para intervenções, coordenação de projeto de extensão e de equipes de teatro, supervisão e discussão dos casos atendidos, pesquisa e orientações à equipe médica, aos doentes, 
familiares e cuidadores. De todas essas funções, $66 \%$ dos relatos indicaram que o trabalho de escuta é específico e prioritário do psicólogo.

Com relação ao histórico do serviço de Psicologia dentro das instituições hospitalares e a forma como inicialmente lidaram com o novo contexto de trabalho, oito profissionais afirmaram que o setor de Psicologia já era minimamente estruturado, existindo antes de seu ingresso na instituição. Entretanto, todos os participantes observaram que trabalham de forma autônoma nesse contexto, com flexibilidade para alterar técnicas, intervenções e atendimentos da maneira que lhes for mais coerente, e afirmaram unânimemente que é preciso engajamento em atividades de formação continuada e de estudo permanente.

Sobre os entraves para o exercício profissional, três aspectos podem ser destacados: 1) o desconhecimento das questões teóricometodológicas quando do ingresso profissional no contexto hospitalar: $38 \%$ dos participantes indicaram que não sabiam como manejar os atendimentos realizados e desconheciam as demais funções que deveriam desempenhar no hospital, 2) adaptação às modalidades de atendimento no hospital: $37 \%$ revelaram dificuldades para atender nos espaços ofertados dentro do hospital, bastante diferentes do consultório particular, além de não saberem lidar com o aspecto dinâmico que essa instituição apresentava em seu cotidiano, o que comprometia o agendamento e o planejamento de suas intervenções, 3) em um índice de $33 \%$, citaram as questões relativas ao preparo pessoal para enfrentar cotidianamente o sofrimento, a morte e as impotências inerentes ao ser humano.

Com um índice de 23\%, houve a indicação de divergência de pensamento com relação aos próprios colegas de trabalho quanto aos encaminhamentos e intervenções, bem como incompatibilidade entre o discurso biomédico e o psicológico de causalidade e de explicação dos processos de adoecimento. Os demais aspectos de dificuldade identificados tiveram cerca de $10 \%$ de apresentação: novidade de emprego, por ter sido realocado de cargo rapidamente, carga horária excessiva para o profissional da saúde mental, tempo limitado para o atendimento a cada paciente, o próprio perfil deste, que é bastante específico, por estar em sofrimento social, físico, financeiro e emocional, tendo o psicólogo que auxiliá-lo a pensar sobre questões de maior amplitude e que estão vinculadas ao atendimento de forma periférica, porém estrutural e significativa, e o desconhecimento da funcionalidade do psicólogo nesse espaço, tanto por parte do paciente como da própria equipe de trabalho. Assinala-se, ainda, que quatro participantes comentaram a falta de recursos materiais para o serviço de Psicologia nos hospitais, indicando que é precário o investimento institucional nesse aspecto.

Sobre os dados apresentados pelos coordenadores de curso, verificou-se que os três tinham conhecimento da Resolução n. 8, porém cada instituição exerce a adaptação de forma autônoma, por serem particulares e estaduais. Dentro desse panorama, a primeira das instituições de ensino pesquisadas havia passado por reformulações curriculares após a Resolução n. 8. Os dados de entrevista indicaram que, a partir da nova lei, uma ênfase vinculada à área de saúde foi estabelecida no término do curso como optativa e com estágios curriculares previstos. Existem, nessa instituição, oito disciplinas obrigatórias referentes ao núcleo comum de conhecimentos transmitidos aos alunos, com temáticas indiretamente vinculadas à atuação em saúde, e 23 disciplinas optativas que apresentam temáticas diretamente relacionadas à área. Não são oferecidos projetos vinculados à área, e os discentes têm a possibilidade de realizar três estágios específicos que preparam para a intervenção 
em saúde. O projeto pedagógico desse curso propõe a construção de um olhar dentro de um novo paradigma científico, que exige uma visão holística de homem e que concebe o processo de formação de maneira contínua e auxilia na construção de uma visão abrangente, sem descartar os conhecimentos específicos para o exercício profissional do psicólogo da saúde. Das três instituições pesquisadas, essa é a única que apresenta a disposição em ênfases no curso, com a possibilidade de cursar 1.600 horas/aula de atividades na área. A coordenação entende que os conhecimentos oferecidos preparam para a atuação dos egressos em hospitais.

Os dados obtidos no contato com a segunda instituição pesquisada revelaram que os conhecimentos ministrados na graduação em Psicologia não são suficientes para a atuação na área hospitalar, o que indica a necessidade de formação continuada para os egressos do curso. Essa instituição oferece 12 disciplinas no núcleo comum do curso, referentes à atuação em contextos de saúde, sem a possibilidade de disciplinas optativas. Os graduandos têm a alternativa de fazer um projeto de extensão na área e os estágios obrigatórios do final do curso podem ser realizados em instituições de saúde, com a possibilidade de se cursar 1.100 horas/aula de atividades na área. A entrevista indicou que não foi feita adequação à Resolução n. 8, embora o projeto-político pedagógico do curso estivesse em reformulação no período da pesquisa. Houve apenas mudanças com relação à disposição de determinadas disciplinas nas séries e à nomenclatura utilizada para elas.

A terceira instituição pesquisada passou por algumas reformulações, entendidas pela coordenação como importantes para a formação de cidadãos críticos e articuladores dos diferentes saberes e habilidades pertinentes ao psicólogo, mas afirmou que a nova legislação não trouxe significativas novidades para o contexto acadêmico em questão, corroborando o que já vinha sendo feito e pensado em tempos anteriores. Com relação às atividades do curso vinculadas aos conhecimentos pertinentes à atuação em contextos de saúde, existem 12 disciplinas obrigatórias, oferecidas no núcleo comum, e 4 optativas diretamente relacionadas à intervenção psicológica em instituições de saúde, que permitem cursar 1.332 horas/aula de atividades na área. Além disso, existem 10 projetos de pesquisa e 5 projetos de extensão voltados para a discussão e a elaboração de conhecimento científico, que podem ser aplicados na comunidade atendida por esses serviços. De acordo com os dados coletados, a área clínica está presente ao longo de todo o curso de Psicologia dessa instituição, auxiliando na formação e na posterior atuação dos estudantes em quaisquer contextos, conforme abordado pela coordenação, e os congressos e os demais eventos de que tais estudantes participam também são concebidos como fundamentos para a compreensão de seu trabalho em instituições de saúde. Perguntas como: qual é o reconhecimento e o espaço que o psicólogo hospitalar tem nesses contextos por parte dos demais profissionais da área da saúde? Quais os conhecimentos que outras áreas impõem à Psicologia e como isso está sendo articulado na nova lei? Na visão dessa coordenação, esses são pontos a serem discutidos, uma vez que existe competição na área, sendo crucial a promoção de políticas públicas para que o psicólogo tenha efetivo acesso a esse campo, aos recursos e à população, evitando o simples ajuste a demandas e a instâncias administrativas.

A última coordenação citada afirmou que questões institucionais perpassam e até travam o processo de reformulação curricular, contudo, modificações estão sendo consideradas e propostas para que haja uma integração dos conteúdos ministrados em cada série. A coordenação acrescentou que a assimilação acrítica das ideias propostas na legislação brasileira é um fator importante a ser refutado. Segundo essa coordenação, o profissional de 
Psicologia deve ser capaz de identificar os fundamentos teórico-políticos que embasam tais reformulações, pois a adequação desmedida às questões mercadológicas pode promover uma descaracterização da identidade do psicólogo e da especificidade de sua atuação, independentemente do contexto.

\section{Discussão}

Observou-se que a maior parte dos participantes tinha uma considerável experiência na área hospitalar e que haviam se graduado anos antes da elaboração e da vigência da Resolução n. 8, o que sugere que a formação acadêmica, provavelmente, estava dentro do viés biomédico e fragmentado citado pelo CFP (2006), e não dentro de uma formação mais articulada com a prática profissional e com o entrelaçamento de conteúdos, como prioriza a lei referida nesse estudo. Portanto, os conhecimentos empregados na atuação cotidiana em hospitais advieram, majoritariamente, da prática profissional e de atividades extracurriculares à graduação em Psicologia, sendo esta última menos reconhecida como significativa no processo de formação profissional do que as atividades feitas à parte por iniciativa pessoal.

A respeito da pouca sistematização dos conhecimentos e das intervenções do profissional de Psicologia nas instituições de saúde, Costa Júnior comenta que existe uma questão de exigência profissional e mercadológica que é diferente da carreira formativa do psicólogo: a necessidade do uso de uma metodologia científica e de sua aplicação nas investigações sistemáticas desenvolvidas nos espaços médicos, em esquemas multidisciplinares. Há a falta de estruturação do trabalho, destituído de um planejamento prévio e específico, e a variação, a depender do contexto, das intervenções aplicadas e dos conhecimentos empregados, sem a consolidação de uma ciência psicológica. A formação deficitária, no entendimento de Angerami-Camon (2002), advém da recente formalização da área na Psicologia bem como das dificuldades de se definir a prática do psicólogo em virtude das muitas leituras teóricas existentes na área, não havendo uma unicidade teórica e metodológica nessa profissão.

Além disso, segundo Angerami-Camon (2002), as questões institucionais acabam por delimitar e limitar a atuação desse profissional, estando o trabalho do psicólogo influenciado por muitas variáveis contextuais, acrescidas das dificuldades das questões peculiares dos atendimentos. Esse profissional enfrenta dificuldades com o contexto institucional de maneira ampla, o que implica a necessidade da formação acadêmica contemplar tal aspecto, e não apenas pontos específicos do ambiente hospitalar. Sobre tais conhecimentos, a Resolução n.8 afirma, em seu art. 7o, que "o núcleo comum da formação em Psicologia estabelece uma base homogênea para a formação no País e uma capacitação básica para lidar com os conteúdos da Psicologia, enquanto campo de conhecimento e de atuação" (2004, p. 4), e, no art. 14, afirma que "a organização do curso de Psicologia deve, de forma articulada, garantir o desenvolvimento das competências do núcleo comum, seguida das competências das partes diversificadas - ênfases - sem concebê-los, entretanto, como momentos estanques do processo de formação" (2004, p. 7). Com relação ao estabelecimento de ênfases, segundo a Resolução n. 8, art. 11, §1으, essas devem consistir em um "subconjunto de competências e habilidades dentre aquelas que integram o domínio das competências gerais do psicólogo, compatível com demandas sociais atuais e/ou potenciais, e com a vocação e condições da instituição" (2004, p.6), abordando em lei o que se faz como necessidade.

Contudo, tanto os contextos de trabalho quanto os ambientes formativos parecem desconhecer o que deve ser exigido do egresso ou, ao menos, as formas de construção para 
tanto. A incapacidade de contemplar todos os conhecimentos da área na graduação é fato, porém a afirmativa de esse nível de formação não ser suficiente para a atuação nos hospitais é parcialmente consistente. Lembramos que a Resolução n. 8 apresenta a graduação como etapa de formação que é responsável pelo acesso a uma amplitude de saberes e de conhecimentos que possam ceder um mínimo de fundamentos para exercício profissional em núcleos específicos de atuação, ainda que de forma iniciante e breve, o que ficou evidente no discurso unânime dos participantes acerca da formação continuada.

$\mathrm{Na}$ amostra pesquisada, percebeu-se que a formação na graduação em Psicologia não contempla as particularidades necessárias para o trabalho no hospital, embora uma das instituições possua mecanismos mais concretos de veiculação de conhecimentos afinados com a realidade hospitalar. Na prática, o que se vê é que a multiplicidade de conhecimentos exigidos pelo profissional é muito mais abrangente e de ordem dinâmica e contextual, extrapolando o saber estritamente psicológico e clínico originariamente ministrado nas instituições de ensino superior, hipótese advinda da discrepância verificada entre o relato dos coordenadores dos cursos e o coletado com os profissionais que trabalham na área da saúde.

Os fundamentos teóricos e metodológicos utilizados nas intervenções não possuem uma vinculação direta à formação adquirida pelos profissionais de Psicologia no ensino superior, ainda que dois dos coordenadores entrevistados afirmem que a formação oferecida pelas faculdades é coerente e suficiente para o trabalho. Verificou-se que as grades curriculares dos cursos de Psicologia pesquisados em Londrina contemplam disciplinas que auxiliam nas discussões no setor da saúde, mas de maneira periférica, focando aspectos mais técnicos e específicos do fenômeno psicológico. As dificuldades encontradas pelos psicólogos nas instituições de saúde que atuam extrapolam, em sua maioria, a formação própria da ciência psicológica, que conta com questões administrativas, de manejo e de adaptação ao contexto específico de trabalho, e não somente aos aspectos técnicos e de conhecimentos específicos do campo, ainda que esses pontos também tenham sido abordados. Afirmações a respeito da prática assistemática com que trabalham bem como o relato de que se sentiram inicialmente perdidos no novo espaço sugerem que a graduação cedeu parcialmente o embasamento para o exercício profissional, demandando outras habilidades do egresso.

\section{Conclusões}

Embora se reconheça a limitação da amostra pesquisada nesse estudo no que tange à realidade nacional dessa temática, a construção de um pensamento científico sobre a formação do psicólogo e a prática profissional em saúde, em especial no campo hospitalar e na realidade pesquisada, pôde ser alcançada, produzindo reflexão a respeito da legislação proposta pelo Conselho Nacional de Educação e a realidade profissional do campo estudado. As universidades estão em processo de construção das novas demandas acadêmicas estabelecidas, assim, é fundamental a realização de pesquisas sobre as adaptações curriculares e a elaboração dos projetos político-pedagógicos dos cursos de Psicologia no País. Na mesma direção, é relevante a construção de estudos sobre a prática dos psicólogos na área da saúde, ainda tida como área emergente na profissão. Estamos no caminho, conforme verificado em algumas mudanças curriculares e no relato de profissionais formados há menos tempo, mas são necessárias avaliações sistemáticas sobre a correlação entre a formação dada e a prática dos profissionais na área da saúde, a de fim aprimorar a adequação entre o ensino e o trabalho de forma mais eficaz e satisfatória para os profissionais e para os usuários desses serviços. 
Questionário utilizado com os psicólogos das instituições de saúde na pesquisa de Psicologia hospitalar, na cidade de Londrina $-P R$

Dados de identificação:

Idade:

$\operatorname{Sexo}() M() F$

Local da graduação:

Formado há quanto tempo?

( ) Há menos de cinco anos

( ) Entre cinco e dez anos

( ) Há mais de dez anos

- Na sua formação acadêmica, em nível de graduação, você obteve conhecimentos relacionados à área de atuação na saúde?

( ) Sim

( ) Não

Se sim, especifique.

Os conhecimentos adquiridos através das atividades acadêmicas auxiliaram na sua prática de forma coerente e apropriada, desvelando a realidade hospitalar de sua atuação profissional?

Quais foram os desafios mais significativos que encontrou nessa prática?

Quais tipos de práticas de atendimento psicológico você utiliza no hospital?

O trabalho que você desenvolve nessa instituição era uma atividade já pensada anteriormente por outros profissionais e já bem estruturada ou você teve que iniciar esse trabalho a partir de suas próprias ideias? Se sim, como desenvolveu e construiu sua prática?

A partir dos conhecimentos e experiências que apresenta, sente necessidade de participar de atividades de formação continuada para melhorá-los? 
Questionário utilizado com os coordenadores dos cursos de graduação na pesquisa de Psicologia hospitalar, na cidade de Londrina - PR

1- Há quanto tempo o curso funciona na instituição? Qual é a data de aprovação desse curso pelo MEC?

2- Qual é o tempo em que o projeto/grade curricular investigado está sendo aplicado?

3- Com relação às Diretrizes Curriculares Nacionais para os cursos de graduação em Psicologia, de 2004, quais alterações foram feitas para adequar a formação ofertada por essa instituição de ensino superior à mesma, relacionadas à saúde?

4- No que se refere às atividades destinadas à formação de profissionais de Psicologia na área da saúde, qual a carga horária total no curso destinada a atividades nesse ramo?

5- Quais os tipos de atividades ofertadas pela faculdade referentes à área de atuação específica da saúde, incluindo estágios, disciplinas teóricas obrigatórias e optativas?

6- Nos projetos anteriores, já havia atividades da área da saúde? E no atual, como essas atividades estão distribuídas ao longo do curso?

7- Você acredita que os conhecimentos ofertados sejam suficientes para a prática profissional dos egressos do curso de Psicologia na área de saúde? Se existem críticas sobre esses aspectos, quais seriam? 


\section{Zeila Facci Torezan}

Doutora em Psicologia pela Universidade Federal de Santa Catarina e professora do curso de Psicologia do Centro Universitário Filadélfia e da Pontifícia Universidade Católica do Paraná, Londrina - PR - Brasil.

E-mail: zeilatorezan@hotmail.com

\section{Taís da Costa Calheiros}

Discente do curso de Psicologia do Centro Universitário Filadélfia, Londrina - PR - Brasil.

E-mail: calheirostais@gmail.com

\section{Jéssica Pedrosa Mandelli}

Discente do curso de Psicologia do Centro Universitário Filadélfia, Londrina - PR - Brasil.

E-mail: jessicamandelli@hotmail.com

\section{Vanuccy Martins Stumpf}

Discente do curso de Psicologia do Centro Universitário Filadélfia, Londrina - PR - Brasil.

E-mail: vanuccy.stumpf@gmail.com

\section{Endereço para envio de correspondência:}

Rua Assis Vicente, 105, Recanto do Salto. CEP: 85055-710. Londrina, PR

Recebido 09/02/2012, 1a Reformulação 25/11/2012, Aprovado 29/11/2012

\section{Referências}

Angerami-Camon, V. A. (2002). O ressignificado da prática clínica e suas implicações na realidade da saúde. In V. A. Angerami-Camon (Org.). Psicologia da saúde: um novo significado para prática clínica (Cap. 1). São Paulo: Pioneira Thomson Learning.

Branco, M. T. C. (1998). Que profissional queremos formar? Psicologia: Ciência e Profissão, 18(3), 28-35.

Conselho Federal de Psicologia. (2006). Diálogos. Saúde e psicologia: os desafios teóricos e práticos e as conquistas no cuidado com o sujeito. Brasília, DF: Autor

Costa, Á. L., Jr. (1997). Psicologia da saúde: uma proposta de renovação de modelos clínicos tradicionais. Revista InsightPsicoterapia, 7(80), 24-27.

Costa, Á. L., Jr. (2010). Psicologia da saúde: pesquisa e intervenção profissional. In Anais, I Congresso de Psicologia e Análise do Comportamento: Diversidade, Integração e Sustentabilidade (pp. 26-27). Londrina, PR: Universidade Estadual de Londrina.

Gioia-Martins, D., \& Rocha, A., Jr. (2001). Psicologia da saúde e o novo paradigma: novo paradigma? Revista Psicologia: Teoria e Prática, 3(1), 35-42.

Matarazzo, J. D. (1980). Behavioral health: A 1990 challenge for the health sciences professions. In J. D. Matarazzo, Sh. M.
Weiss, J. A. Herd, N. E. Miller \& St. M. Weiss (Eds.). Behavioral health: A handbook of health enhancement and disease prevention (pp. 3-40). N. York: Wiley.

Minayo, M. C. de S. (2008). O desafio do conhecimento: pesquisa qualitativa em saúde (11a.ed.). São Paulo: Hucitec.

Moura, E. P. G. de. (1999). A psicologia (e os psicólogos) que temos e a psicologia que queremos: reflexões a partir das propostas de Diretrizes Curriculares (MEC/SESU) para os cursos de graduação em psicologia. Psicologia: Ciência e Profissão, 19(2), 10-19.

Resolução n. 8, de 7 de maio de 2004. (2004). Institui as Diretrizes Curriculares Nacionais para os cursos de graduação em Psicologia, propostas pelo Conselho Nacional de Educação, na Câmara de Ensino Superior. Brasília, DF. Recuperado em 10 mar., 2010, de http://portal.mec.gov.br/index. php?option $=$ com_content\&view $=$ article\&id $=12991$.

Speroni, A. V. (2000). O lugar da psicologia no hospital geral. Monografia, Instituto de Psicologia, Universidade do Estado do Rio de Janeiro, Rio de Janeiro, RJ.

Spink, M. J. P. (2009). Psicologia social e saúde: práticas, saberes e sentidos (6a. ed.). Petrópolis, RJ: Vozes.

Weber, S. (1985). Currículo mínimo e o espaço da pesquisa na formação do psicólogo. Psicologia: Ciência e Profissão, 5(2), 11-13. 